THE additions to the Zoological Society's Gardens during the past week include two Macaque Monkeys (Macacus cynomolgus) from India, presented respectively by Capt. E. Waterhouse and Mr. Samuel Thomson; a Common Roe (Capreolus caprea) from Greece, presented by Mr. Edward Jones; a Common Jackal (Canis aureus) from India, presented by Capt. Easson; a Common Seal (Phoca vilulina), European, presented by Messrs. Thompson and Gough; a Bornean Fireback (Euplocamus nobilis) from Borneo, presented by Mr. A. Dent; two Mandarin Ducks (Aix galericulata) from China, presented by Mr. Edward Trelawny; a Common Marmoset (Hapala jacchus), a Tuberculated Lizard (Iguana tuberculatu), a Teguexin Lizard (Teius tegutexin), a Merrem's Snake (Liophis merremi), a Black-headed Snake (Homalocranion melanocephalum), a Plumbeous Snake (Oxyrhopus plumbeus), a d'Orbigny's Snake (Heterdond'orbignyi), an Anaconda (Eunectes murinus) from South America, purchased ; a Collared Fruit Bat (Cynonycteris collaris), bornin the Gardens.

\section{A NEW GALVANOMETER FOR STRONG CURRENTS}

$\mathrm{N}$ the following principle an ordinary tangent galvanometer can be transformed into an instrument suitable for the measurement of strong currents such as produced by powerful magneto-or dynamo-electric machines.

Suppose the circular coil of a tangent galvanometer mounted so as to turn round its horizontal diameter lying in the meridian, and assume the needle to be freely movable in all directions, then the effect which the current produces ipon the magnet at different inclinations of the coil to the horizontal plane is as follows :-

Ist. If the ring is in the vertical position (in the meridian) we have the ordinary form of tangent galvanometer, for which

$$
\tan \alpha=\frac{k I}{H} \text {.... }
$$

where $\alpha$ is the deflection of the needle in the horizontal plane, $I$ the strength of the current, $k$ a constant depending upon the dimensions of the coil, and $H$ the horizontal component of the earth's magnetism.

2nd. If the ring is in the vertical position the magnet is only deflected in the plane of the meridian, and the deflection is determined by

$$
\tan \beta=\frac{k T}{V} \cdot \cdot \cdot \cdot \cdot
$$

where $\beta$ is the deflection and $V$ the vertical component of the earth's magnetism. This would be a tangent galvanometer in which the directive force of the current is opposed by the vertical component of the terrestrial magnetism.

By the combination of these two formula we obtain

$$
\frac{\tan \alpha}{\tan \beta}=\frac{V}{I I} \text {. }
$$

Hence, the tangents of the two deflections are in inverse pro. portion respectively to the two components of the earth's magnetism.

Since $\frac{V}{H}=\tan i$, where $i$ is the "magnetic dip," this relation may be used to ascertain the "dip" by a method similar to that of Prof. Wilhelm Weber by the inductive action of the earth.

$3 \mathrm{rd}$. If the ring is neither in the vertical nor in the horizontal position, but is inclined at any angle $\phi$ to the horizontal plane, the magnet is simultaneously defiected from the plane of the meridian through an angle $\alpha$ and from the horizontal plane through an angle $\beta$. In this case we have to introduce, instead of $k$ in the equations $I$ and 2 respectively, $k \sin \phi$ and $k \cos \phi$, whereby they become

$$
\begin{aligned}
\tan \alpha & =\frac{\hbar I}{H} \cdot \sin \phi . . . \\
\tan \beta & =\frac{\hbar I}{V} \cdot \cos \phi . . .
\end{aligned}
$$

Combining these two equations we obtain the formula

$$
\frac{\tan \alpha}{\tan \beta} \cot \phi=\frac{V}{H}=\tan i \text {, }
$$

$\phi$ being know. and $\alpha$ and $\beta$ read off, the "dip" may be found by such measurements without altering the inclination of the coil.

If the ring is gradually brought from the vertical to the horizontal position, whilst a current $I$ passes through it, the deflection $\alpha$ decreases proportionally from the maximum $\tan \alpha=\frac{k I}{H^{-}}$ to zero. At the same time the deflection $\beta$ increases from zero to the maximum $\tan \beta=\frac{k I}{V}$.

For practical measurements we need only consider the deflection $\alpha$ in the horizontal plane, and for this reason the needle should work on a vertical axle pivoted at both ends.

With this form of instrument I was enabled to measure very strong currents.

It will be readily understood that a current which would throw the needle to nearly $90^{\circ}$ when the ring is vertical, will, when it is suitably inclined, only deflect the needle to that part of the scale $\left(45^{\circ}\right)$ where readings are most accurate.

If the instrument and place of observation remain the same, we can substitute in equation (3) a new constant $K$ for $\frac{k}{H}$ whereby it is simplified to

$\tan \alpha=K I \sin \phi$.

Further we have for other currents $I_{1}, I_{2}$, \&c., at other angles of inclination $\phi_{1}, \phi_{2}$, \&c.

$$
\begin{aligned}
& \tan \alpha_{1}=K I_{1} \sin \phi_{1}, \\
& \tan \alpha_{2}=K I_{2} \sin \phi_{2}, \text { \&c., }
\end{aligned}
$$

hence,

$\alpha_{1}: \tan a_{2} \ldots \doteq I \sin \phi: I_{1} \sin \phi_{1}: I_{2} \sin \phi_{2}, \& \mathrm{c}$.

$$
\text { or } I: I_{1}: I_{2} \ldots=\frac{\tan \alpha}{\sin \phi}: \frac{\tan \alpha_{1}}{\sin \phi_{1}}: \frac{\tan \alpha_{2}}{\sin \phi_{2}} \ldots
$$

By this relation different currents measured at different incli nations of the ring can be compared.

The following separate cases may serve as further illustrations :-

Case I. Currents of different strength $I_{1}, l_{1}, I_{2} \ldots$, sent through the coil at the same inclination $\phi$, give$\tan a: \tan \alpha_{1}: \tan \alpha_{2} \ldots=I: I_{1}: I_{2} \ldots$

Therefore the law of tangents holds also for the inclined ring. Case 2. The same current $I$ sent through the ring at different angles of inclination $\phi, \phi_{1}, \phi_{2} \ldots$ gives

$\tan \alpha: \tan \alpha_{1}: \tan \alpha_{2} \ldots=\sin \phi: \sin \phi_{1}: \sin \phi_{2} \ldots$

$$
\text { or } \frac{\tan \alpha}{\sin \phi}: \frac{\tan \alpha_{1}}{\sin \phi_{1}}: \frac{\tan \alpha_{2}}{\sin \phi_{2}}=\ldots=C
$$

where $C$ a constant.

The tangents of the deflections are therefore in the same proportion as the sines of the inclinations; or in other words, the tangents of the defiections divided by the sines of the corresponding inclinations give for the same strength of current a constant value.

Case 3. For different currents $I, I_{1}, I_{3} \ldots$ sent through the ring at inclinations $\phi, \phi_{1}, \phi_{2} \ldots$ giving the same deflection a (say of $45^{\circ}$ ) we have

$$
I: I_{1}: I_{2}: \ldots=\frac{\mathrm{r}}{\sin \phi}: \frac{\mathrm{r}}{\sin \phi_{1}}: \frac{\mathrm{r}}{\sin \phi_{2}} \cdots
$$

$=\operatorname{cosec} \phi: \operatorname{cosec} \phi_{1}: \operatorname{cosec} \phi_{2} \ldots$

and the instrument thus used acts as a cosecant galvanometer.

The instrument which I used to ascertain the degree of accuracy of the method described consisted of a wooden ring of $30 \mathrm{~cm}$. diameter, wound for some experiments with a few convolutions of wire, and for other experiments with a copper band. This ring, in the centre of which a small magnetic needle was placed, could be turned round its horizontal diameter, and its inclination read off on a graduated quadrant. To adjust the instrument the ring is approximately placed in the horizontal position; a current is then sent through the coil, and if the needle is deflected from the meridian, the inclination of the ring must be carefully altered until no deflection occurs. In this position the quadrant is fixed so that its zero point coincides with the index attached to the coil, and the instrument is now ready for use.

The following tables contain records of some of the experiments made with this instrument :-

Table I. gives the results obtained with a coil of seven convo. Iutions of wire of '074 Siemens' units resistance, and with a needle turning on a point. One Bunsen's cell was used, and the strength of current varied by the introduction of resistances. For each current-strength readings were taken at inclinations of the ring, the sines of which are proportional to the even integers 2 to 10. 
TABle I.

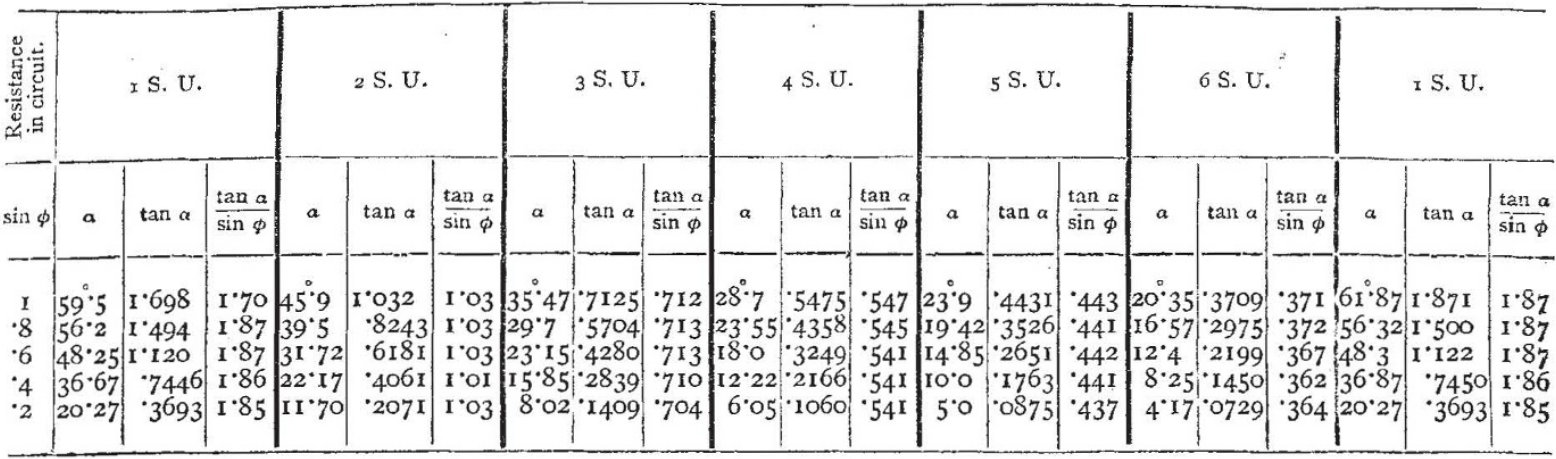

It will be seen from this table that the value of $\frac{\tan a}{\sin \phi}$ is as nearly a constant as can be expected from this lind of measurement.

Table II. gives the results obtained with the same coil and needle as before, but with the current unaltered in strength (one Bunsen's cell suitably reduced by the insertion of a small resist. ance). The order of experiments is showi by the arrows,

TABLE II.

\begin{tabular}{|c|c|c|c|c|c|c|c|c|c|}
\hline & \multicolumn{3}{|c|}{ I. } & \multicolumn{3}{|c|}{ II. } & \multicolumn{3}{|c|}{ III. } \\
\hline $\sin \phi$ & $a$ & $\tan \alpha$ & $\frac{\tan a}{\sin \phi}$ & $a$ & $\tan a$ & $\frac{\tan \alpha}{\sin \varphi}$ & $a$ & $\tan a$ & \\
\hline · I & $10 \div 4$ & $\cdot 1835$ & $r \cdot 8_{3}$ & 1025 & -1808 & $\mathrm{I} \cdot 8 \mathrm{r}$ & So․ 25 & $\cdot x 808$ & \\
\hline 2 & $20 \% 2$ & 3679 & $1 \cdot 84$ & $20^{\circ} 15$ & 3669 & 1.83 & $\mid=20.15$ & $\cdot 3669$ & \\
\hline 3 & $\checkmark 29^{\circ}$ & $\cdot 5566$ & $1 \cdot 85$ & $29^{\circ} 05$ & 5554 & $\begin{array}{r}1.85 \\
\end{array}$ & $\psi_{29^{\circ}}^{\circ}$ & 5543 & \\
\hline 4 & 36.95 & 7522 & $1 \cdot 88$ & $36 \cdot 75$ & $\cdot 7467$ & $\mathrm{I} \cdot 87$ & 36.65 & $\cdot 7440$ & \\
\hline 5 & 42.95 & 9309 & $\mathrm{I} \cdot 86$ & 42.85 & 9276 & 1.85 & $42 \cdot 95$ & 9309 & I \\
\hline 6 & $48 \cdot 15$ & $I \cdot 116$ & $1 \cdot 86$ & $48 \cdot 15$ & $\mathrm{I} \cdot \mathrm{I} 6$ & $r \cdot 86$ & $48 \cdot \mathrm{I}$ & $1 \cdot 115$ & \\
\hline 7 & 52.45 & $I^{\prime} 301$ & 1.86 & 52.5 & I. 303 & 1.86 & 52.45 & $I \cdot 30 I$ & \\
\hline$\cdot 8$ & $56 \cdot 2$ & r.494 & $\mathrm{I}: 87$ & 个 $56^{\circ} 05$ & $x \cdot 485$ & I.86 & $56 \cdot 2$ & I. 494 & \\
\hline '9 & $59^{\circ} \mathrm{I}$ & 1.671 & $1 \cdot 86$ & $59^{\circ} \mathrm{I}$ & $1 \cdot 67 \mathrm{I}$ & I.86 & $59^{\circ} \mathrm{I}$ & 1.671 & \\
\hline I & $6 \mathrm{I} \cdot 9$ & 1.873 & & & $r \cdot 865$ & I.86 & $6 r^{\circ} 7$ & 1.857 & \\
\hline
\end{tabular}

The smaller value of the constant at the top of each column is doubtless due to slight mechanical inaccuracies in this experi. mental instrument.

Table III. gives the results obtained with the copper band provided with stout leading wires and with the needle fixed to an axle. The resistance of the copper band, including the leads, was only 'oor Siemens' units. Three Bunsen's cells connected parallel were used without additional resistance.

TABLE III.

\begin{tabular}{|c|c|c|c|}
\hline $\sin \phi$ & $a$ & $\tan \alpha$ & $\frac{\tan a}{\sin \phi}$ \\
\hline $\begin{array}{l}\mathbf{1} \\
\cdot 8 \\
\cdot 6 \\
\cdot 5 \\
\cdot 4 \\
\cdot 2 \\
\cdot 1 \\
1\end{array}$ & $\begin{array}{l}66^{\circ} \cdot 9 \\
61 \cdot 6 \\
54 \cdot 4 \\
49 \cdot 4 \\
42 \cdot 9 \\
25 \cdot 1 \\
13 \cdot 2 \\
66 \cdot 8\end{array}$ & $\begin{array}{r}2 \cdot 344 \\
\mathrm{r} \cdot 849 \\
\mathrm{I} \cdot 397 \\
\mathrm{I} \cdot \mathrm{r} 67 \\
\cdot 9293 \\
\cdot 4684 \\
\cdot 2345 \\
2 \cdot 333\end{array}$ & $\begin{array}{l}2 \cdot 34 \\
2 \cdot 31 \\
2 \cdot 33 \\
2 \cdot 33 \\
2 \cdot 32 \\
2 \cdot 34 \\
2 \cdot 34 \\
2 \cdot 33\end{array}$ \\
\hline
\end{tabular}

In this table the greatest difference from the mean of the constant $\left(2^{*} 33\right)$ is not more than $\cdot 8$ per cent.

The foregoing experiments having shown that the measurements with this instrument are, as to exactness, in no way inferior to those with the usual form of tangent galvanometer, I also employed it for the currents of dynamo-electric machines.

The first of these experiments was made with a Siemens' machine of smallest size. Besides the galvanometer an electric lamp was in circuit. The strength of the current and the intensity of the light was measured, and at the same time the number of revolutions of the armature counted. The results are given in the next table.

TABLE IV.

\begin{tabular}{c|c|c|c|c}
\hline $\begin{array}{l}\text { Revolutions } \\
\text { of armature. }\end{array}$ & $\begin{array}{c}\text { Deflection } a \\
(\sin \phi=\cdot 2)\end{array}$ & $\tan a$ & $\frac{\tan a}{\sin \phi}$ & $\begin{array}{c}\text { Intensity of } \\
\text { light in } \\
\text { standard } \\
\text { candles. }\end{array}$ \\
\hline 850 & 38 & 7813 & $3 \cdot 906$ & 3200 \\
851 & 37 & 7536 & $3 \cdot 768$ & 2750 \\
\hline
\end{tabular}

The second experiment was made in the same way as the pre. ceding, but with a Siemens' machine of medium size. 'The results are given in

TABLE V.

\begin{tabular}{c|c|c|c|c}
\hline $\begin{array}{c}\text { Revolutions } \\
\text { of armature. }\end{array}$ & $\begin{array}{c}\text { Deflection } \alpha \\
(\sin \phi=\cdot x)\end{array}$ & $\tan a$ & $\frac{\tan a}{\sin \phi}$ & $\begin{array}{c}\text { Intensity of } \\
\text { light in } \\
\text { standarc } \\
\text { candles. }\end{array}$ \\
\hline 660 & 28 & 5317 & $5 \cdot 317$ & 4100 \\
696 & $33^{\circ} 5$ & .6619 & 6.619 & 6400 \\
692 & 33 & .6494 & 6.494 & $7700^{2}$ \\
\hline
\end{tabular}

The deflections in the experiments with the small machine were taken with the galvanometer ring at an inclination, the sine of which is equal to 22 ; with the larger machine the sine of the angle of inclination was equal to ' 1 . The column headed $\frac{\tan \alpha}{\sin }$ gives in both cases the tangent of the defiection which would be obtained with the vertical ring.

By these two tables I intend merely to show that even such powerful currents which give a light of thousands of candles produce readable deflections with a suitable inclination of the ring.

I may add that the method I have just described to reduce the action of a coil upon the magnetic needle by turning it round a horizontal axis will scarcely be limited to the tangent gaivanometer, but that this method very likely can be used with other galvanometric apparatus for many purposes where shunts are not desirable. EUGEN OBACH

\section{GULF-WEED}

FROM the time of Columbus to the present day the gralf-weed growing in the "Saroasso Sea" has attracted the attention and excited the interest of all voyagers who have crossed the $I$ With other carbon points than used before.

2 Om de under Korvetten Fosephines.. expedition, sistliden sommar (1869), insmlade Algerne. Af J. G. A ardh, Ofversigt af Kongl. Vetenskaps. $A$ ka. insamlade Algerne. Af J. G. Agardh, Ofversigt af Kongl. Vetenskaps-Aka-
demiens Förhandlingar, 1870 . No. 4, Stockholm. demiens Förhandlingar, 1870 . No. 4 , Stockholm.
Enumeration of Algæ collected by Mr. Moseley, Naturalist to H.M.S. Challenger, at St. Thomas, Bermudas, Coast of Brazil, Cape de Verde Islands, St. Paul's Rocks, Fernando de Noronha, 'Tristan d'Acunha, Inaccessible Island, Simon's Bay, Seal Island, Marion Island, Heard Innean and Kerguelen's Island. By Prof. G. Dickie, M.D., F.L.S., Linnean 